\title{
LC-MS/MS-Based Assay for Free and Deconjugated Testosterone and Epitestosterone in Rat Urine and Serum
}

\section{Carl Jenkinson ${ }^{1}$, Nawed IK Deshmukh², Iltaf Shah¹, Gergely Zachár ${ }^{3}$, Andrea D Székely ${ }^{3}$, Andrea Petroczi ${ }^{1}$ and Declan P Naughton ${ }^{1 *}$}

${ }^{1}$ School of Life Sciences, Kingston University, Kingston upon Thames, London, UK

${ }^{2}$ School of Pharmacy and Chemistry, Kingston University, Kingston upon Thames, London, UK

${ }^{3}$ Department of Anatomy, Histology and Embryology, Semmelweis University, Hungary

\begin{abstract}
Testosterone and epitestosterone are mainly excreted as glucuronides. The aim of this study was to develop and validate a method using liquid chromatography tandem mass spectrometry (LC-MS/MS) to analyse testosterone and epitestosterone in rat serum and urine to assist in vivo studies on steroid metabolism. The method was developed by spiking charcoal stripped rat plasma and urine with the analytes. The developed method was then applied to serum $(n=6)$ and urine samples $(n=6)$ from young male brown Norway rats to determine testosterone and epitestosterone concentrations. The assay showed linearity within quantification range coefficient $\left(\mathrm{r}^{2}\right)$ values above 0.991 . Optimum conditions were determined for the deconjugation of glucuronidated testosterone and epitestosterone along with the internal standard stanozolol D3. Accuracy, precision and extraction recovery for both compounds was satisfactory in both matrices. The method was capable of quantifying $0.250 \mathrm{ng} / \mathrm{mL}$ concentrations of testosterone and epitestosterone in $100 \mu \mathrm{L}$ of serum and urine. The average concentrations of free and deconjugated testosterone and epitestosterone found in the rat samples were: urine-201.68 $\pm 90.16 \mathrm{ng} / \mathrm{mL}$ and $85.37 \pm 21.20 \mathrm{ng} / \mathrm{mL}$; serum$363.40 \pm 11.615 \mathrm{ng} / \mathrm{mL}$ and $1.75 \pm 0.118 \mathrm{ng} / \mathrm{mL}$, respectively. This method is sensitive, specific and reproducible for the determination of free and deconjugated testosterone and epitestosterone in rat serum and urine. The method can be used for in vivo analysis for further investigations of testosterone and epitestosterone concentrations in studies monitoring endocrine dysfunctions and doping.
\end{abstract}

Keywords: Bioanalytical methods; Biological samples; Clinical/ biomedical analysis; HPLC

\section{Introduction}

The 2014 World Anti-Doping Agency (WADA) Prohibited List shows testosterone and epitestosterone listed as class S1.1a and S1.1b, with its use banned in and out of competition [1]. Doping with testosterone is suspected if the urinary ratio of testosterone over epitestosterone (T/E) exceeds 4 [2]. According to the 2012 (WADA) laboratory statistics, elevated testosterone based on the testosterone over epitestosterone (T/E) ratio accounts for $55.5 \%$ of atypical findings within the anabolic agents' drug class from a total of 2,279 for all anabolic agents, which constitute half of all adverse and atypical findings [3]. This T/E ratio approach to testing for testosterone abuse is only accurate if testosterone and epitestosterone are metabolised at the same rate and no other external factors or inter individual factors would alter the metabolism of these steroids [4].

One of the major metabolic pathways in testosterone and epitestosterone regulation and elimination is by glucuronidation through addition of glucuronic acid by UDP-glucuronosyltransferase (UGT) enzymes for excretion in urine. Variations in enzyme preference are observed with UGT $2 \mathrm{~B} 17$ predominating for testosterone glucuronidation, whilst UGT2B7 is the most active UGT for epitestosterone glucuronidation [5]. A variety of effectors of steroid UGT glucuronidation have been identified, including pharmacogenetic variations resulting in different UGT2B17 expression which affects the urinary T/E ratios [6-8]. A number of in vitro studies have identified small molecule inhibitors of UGT2B17 and other UGTs toward testosterone metabolism. These inhibitors include non-steroidal anti-inflammatory drugs diclofenac and ibuprofen [5], flavonoids commonly found in red wine [9] and catechins in green and white tea [10]. As doping tests for testosterone abuse involve deconjugation by $\beta$-glucuronidase to determine total urinary $\mathrm{T} / \mathrm{E}$ ratios, the doping test could be affected by the inhibitory effects of pharmaceuticals and dietary components. Inhibition of testosterone glucuronidation could lead to an increase in testosterone in serum leading to potential adverse health effects. Extending these potentially significant in vitro results to in vivo, experimentation calls for a streamlined analytical procedure that caters for analysing multiple biological samples, such as urine and blood without introducing intra-method variances owing to different sensitivity and specificity.

This report describes a method to determine testosterone and epitestosterone levels in rat serum and urine using liquid chromatography tandem mass spectrometry (LC-MS/MS). Rat models have a number of advantages for controlled clinical trials, including standardised conditions and diet, and testosterone is glucuronidated by phase 2 metabolism as is in humans [11,12]. This method could be applied to such rat studies, where the measurement of testosterone and epitestosterone in these matrices are required through the duration of study.

*Corresponding author: Prof. Declan Naughton, School of Life Sciences Kingston University, Kingston upon Thames, London KT1 2EE, UK, Tel: +44 208 547 7097; Fax: +44 208547 7562; E-mail: D.Naughton@kingston.ac.uk

Received December 16, 2013; Accepted January 15, 2014; Published January 17,2014

Citation: Jenkinson C, Deshmukh NIK, Shah I, Zachár G, Székely AD, et al (2014) LC-MS/MS-Based Assay for Free and Deconjugated Testosterone and Epitestosterone in Rat Urine and Serum. J Anal Bioanal Tech S5: 006. doi:10.4172/2155-9872.S5-006

Copyright: (c) 2014 Jenkinson C, et al. This is an open-access article distributed under the terms of the Creative Commons Attribution License, which permits unrestricted use, distribution, and reproduction in any medium, provided the original author and source are credited. 


\section{Materials and Methods}

\section{Chemicals}

Reference standards for testosterone and epitestosterone and testosterone glucuronide were purchased from Sigma Aldrich (Poole, UK). Epitestosterone glucuronide and stanozolol D3 (internal standard) were purchased from LGC Standards (Teddington, UK). All reference materials had a purity $\geq 98 \%$. Sodium hydrogen phosphate heptahydrate, sodium phosphate monobasic dehydrate, HPLC grade pentane and LCMS grade acetonitrile and water were purchased from Sigma Aldrich (Poole, UK). $\beta$-Glucuronidase from E. coli (Cat No. 03707598001, Lot No. 13931722) was purchased from Roche Diagnostics (Burgess Hill, UK). Rat 4x charcoal stripped $0.2 \mu$ filtered plasma and urine was purchased from Sera Laboratories. A SB C-18 column $(2.1 \mathrm{~mm}, 50 \mathrm{~mm}, 1.8 \mu \mathrm{m})$ and $0.2 \mu \mathrm{m}$ inline filter was purchased from Agilent (Stockport, UK). Syringe driven $0.2 \mu \mathrm{m}$ PTFE filters were purchased from Millipore (Watford, UK). Silanized glass vials where purchased from Sigma Aldrich (Poole, UK).

\section{Animals and samples}

Urine samples were obtained from six male, brown Norway rats (weighing 280-340 g) as part of an independent study [13], purchased from Charles River laboratories (Sulzfeld, Germany). Rats were kept under the conditions and urine samples were collected as described previously [13]. Water and food was available ad libitum. Normal serum samples from six male brown Norway rats were purchased from Sera Laboratories. These rats where approximately 11-12 weeks old weighting between 250-275 g. The serum and urine samples were thawed at $37^{\circ} \mathrm{C}$ and vortex mixed. Aliquots $(100 \mu \mathrm{L})$ were taken from each sample for analysis.

\section{Enzyme hydrolysis of testosterone and epitestosterone gluc- uronide}

The enzyme $\beta$-glucuronidase was used to deconjugate the glucuronide conjugates for the determination of total (glucuronide conjugated+unconjugated) concentration of testosterone and epitestosterone in serum and urine.

\section{Sample purification}

Liquid-liquid extraction was performed using pentane. The mixture was vortex mixed in a glass centrifuge for 20 seconds and centrifuged at $3220 \times \mathrm{g}$ for 10 minutes at $4^{\circ} \mathrm{C}$. The organic layer was transferred to a salinized vial and evaporated under incubation at $40^{\circ} \mathrm{C}$ using a gentle stream of compressed air. The sample were then reconstituted with 100 $\mu \mathrm{L}$ of acetonitrile and filtered through a 0.2 micron PTFE membrane filter for analysis by LC-MS/MS.

\section{Liquid chromatographic-tandem mass spectrometry}

Testosterone and epitestosterone analyses were carried out based on a previous method [14], with modifications, using an LC-MS/MS system comprised of a 1260 infinity LC system (Agilent, Workingham, UK) coupled to a 6430 triple quadruple mass spectrometer (Agilent, Workingham, UK). The LC system comprised of a binary pump, automatic degasser, column heater and 1290 infinity thermostated autosampler. Compounds were separated using a SB C-18 column $(2.1 \mathrm{~mm}, 50 \mathrm{~mm}, 1.8 \mu \mathrm{m})$ that was heated to $45^{\circ} \mathrm{C}$. An inline filter 0.2 micron was used to prevent the analytical column from blocking. The mobile phase consisted of water (solvent A) and acetonitrile (solvent B) with the gradient as follows: 0-5 min (53\% A: 47\% B), 5-9 $\min (53 \%$ A:
$47 \%$ B), 9-11 $\min (0 \%$ A: $100 \%$ B), $11-25 \min (53 \%$ A: $47 \%$ B). The flow rate was $250 \mu \mathrm{L} / \mathrm{min}$ and the injection volume was $4 \mu \mathrm{L}$.

The mass spectrometer was set using electrospray ionisation (ESI) operated in positive ion mode. The protonated molecules, $[\mathrm{M}+\mathrm{H}]^{+}$, of testosterone and epitestosterone $(\mathrm{m} / \mathrm{z} 289.3)$ and stanozolol D3 $(\mathrm{m} / \mathrm{z}$ 332.5) were used as precursor ions for collision induced dissociation (CID) for MS-MS analysis. Multiple reactions monitoring (MRM) mode was used to monitor the precursor ions and diagnostic product ions for each analyte and internal standard based on a previous method [14]. Table 1 details the MRM transitions, collision energy and retention times of testosterone, epitestosterone and stanozolol D3.

The mass spectrometer parameter optimisation was performed using Masshunter optimizer software (version B.03.01). The conditions applied for optimum ionisation were capillary voltage $4000 \mathrm{~V}$, drying gas temperature $325^{\circ} \mathrm{C}$, drying gas flow rate $10 \mathrm{~L} / \mathrm{min}$, nebulising gas pressure 35 psi and fragmentor voltage of $100 \mathrm{~V}$. Masshunter workstation software (LC/MS data acquisition, version B.03.01) was used to control the LC-MS/MS system.

\section{Method validation}

Validation was performed in accordance with Food and Drug Administration (FDA) guidelines to establish sensitivity, specificity, selectivity, linearity, limit of detection, inter and intraday precision and accuracy, percentage recoveries, deconjugation and matrix effects. Steroid free rat plasma and urine were used for method validation.

Calibration curves of known standards were prepared by spiking charcoal-stripped plasma and urine with testosterone and epitestosterone and the internal standard (IS) stanozolol D3. Quality controls (QC) were prepared in the same manner over four concentration ranges of the calibration curve. The calibration curve was plotted for testosterone and epitestosterone levels in plasma and urine by using the analyte to IS ratio. The linearity of the calibration curve was determined using linear analysis.

The accuracy of the method was determined using replicate $(\mathrm{N}=6$, per concentration level) QC samples at four concentration levels and comparing the mean calculated values to the nominal concentration values. Intra-day precision was determined by analysing the six replicated at each concentration level in one day and inter-day precision was performed by analysing 6 replicates at each concentration level over three consecutive days. The relative standard deviation (RSD $\%)$ was used for characterising precision. For the three concentration ranges, an acceptable variability was set at $15 \%$, for the lower limit of quantification (LLOQ) this was set at $20 \%$. LLOQ was determined as the lowest concentration of the analyte that gave a peak response which could be measured with precision and accuracy (RSD less than 20\%).

The absolute extraction recoveries of testosterone and epitestosterone were determined by analysing a blank matrix of plasma and urine that was spiked with a known concentration of analyte and IS that had been extracted with standard solutions prepared in acetonitrile at the same concentrations. The peak area ratios were compared at four

\begin{tabular}{|l|l|l|l|}
\hline Compounds & $\begin{array}{l}\text { Retention Time } \\
(\mathbf{m i n})\end{array}$ & MRM transitions & $\begin{array}{l}\text { Collision energy } \\
(\mathbf{e V})\end{array}$ \\
\hline Testosterone & 8.6 & $289.2>109$ & 22 \\
\hline Epitestosterone & 10.58 & $289.2>97$ & 26 \\
\hline Stanozolol D3 & 11.64 & $289.2>109$ & 21 \\
\hline \multicolumn{3}{|c|}{ Table 1: Analytical parameters for LC and MS. } \\
\hline
\end{tabular}


Citation: Jenkinson C, Deshmukh NIK, Shah I, Zachár G, Székely AD, et al. (2014) LC-MS/MS-Based Assay for Free and Deconjugated Testosterone and Epitestosterone in Rat Urine and Serum. J Anal Bioanal Tech S5: 006. doi:10.4172/2155-9872.S5-006

concentration levels using six replicate samples at each concentration for the extracted and neat samples.

To analyse any effect of the matrix, blank plasma and urine were extracted and then spiked with known concentrations of testosterone, epitestosterone and IS, for comparison to a standard solution at equivalent concentrations in acetonitrile. These samples were prepared over four concentration ranges using replicates of six samples.

To assess the deconjugating activity of $\beta$-glucuronidase, the enzyme was incubated with standard concentrations of testosterone glucuronide, epitestosterone glucuronide and IS in blank plasma and urine over three concentration ranges using replicates of three samples. The samples consisted of blank plasma spiked with urine with $50 \mu \mathrm{L}$ of $\beta$-glucuronidase added and incubated at $50^{\circ} \mathrm{C}$ for two hours. The samples were then cooled in wet ice prior to extraction. The concentration of testosterone and epitestosterone by de-conjugation was compared to samples spiked at the same concentration ranges with testosterone and epitestosterone and IS.

\section{Analysis of testosterone and epitestosterone in rat serum and urine samples}

Samples were prepared as previously described [15] and modified for serum and urine, by adding $100 \mu \mathrm{L}$ of serum or urine to $1 \mathrm{~mL}$ of $0.2 \mathrm{M} \mathrm{pH} 7$ phosphate buffer. The sample was spiked with $50 \mu \mathrm{L}$ of IS stanozolol-D3 to give a concentration of $2 \mathrm{ng} / \mathrm{mL}$. The internal standard was used in order to compensate for variations in instrument injection to injection response and loss of analytes during the extraction procedure. $50 \mu \mathrm{L}$ of $\beta$-glucuronidase enzyme was added and samples where incubated for two hours at $50^{\circ} \mathrm{C}$. The samples were cooled on wet ice and extracted as described above.

\section{Results and Discussion}

\section{Method validation}

The validation results are within the limits set by FDA guidelines. Injection of blank samples of charcoal stripped plasma and urine confirmed no components of the matrices were observed that would interfere with the analytes. Figure 1 shows the chromatogram for extracted analytes in plasma and urine at $0.25 \mathrm{ng} / \mathrm{mL}$.

The assay for urine analysis was linear for testosterone and epitestosterone between concentrations of $0.250 \mathrm{ng} / \mathrm{mL}-1000 \mathrm{ng} / \mathrm{mL}$. Owing to the high range of standards low and high concentration calibrations curves were created for testosterone and epitestosterone. The determination coefficient (r2) values were at or above 0.9917 for testosterone and 0.9997 for epitestosterone in urine and $\mathrm{r}^{2}$ values were at or above 0.9919 for testosterone and 0.9997 for epitestosterone in plasma. Table 2 shows the accuracy, intra-day and inter-day precision results from the assay. The LLOQ for testosterone was found to be $0.250 \mathrm{ng} / \mathrm{mL}$ for testosterone and $0.250 \mathrm{ng} / \mathrm{mL}$ for epitestosterone.

The plasma assay was linear between $0.250 \mathrm{ng} / \mathrm{mL}-1000 \mathrm{ng} / \mathrm{mL}$ for testosterone and epitestosterone. The method was capable of detecting testosterone and epitestosterone at LLOQ of $0.250 \mathrm{ng} / \mathrm{mL}$. The LLOD for testosterone was $0.125 \mathrm{ng} / \mathrm{mL}$ and $0.250 \mathrm{ng} / \mathrm{mL}$ epitestosterone. The extraction recoveries for testosterone and epitestosterone are shown in Table 3 .

Table 4 shows the comparisons from the plasma and urine matrix effects between samples of plasma that have been extracted and spiked with standard concentrations in acetonirile.

The deconjugation assay confirmed the $\beta$-glucuronidase enzyme was effective in de-conjugating testosterone and epitestosterone with the concentration and incubation for the concentrations shown in Table 5 .

\section{Application of method for determination of testosterone and epitestosterone in real samples of rat serum and urine}

The validated method was applied to determine the total (free and de-glucuronidated) testosterone and epitestosterone in rat serum and urine samples. Table 6 shows the total analyte concentrations in a selection of rat urine samples. The average urinary testosterone and epitestosterone concentrations were $201.68 \pm 90.16 \mathrm{ng} / \mathrm{mL}$ and 85.37 $\pm 21.20 \mathrm{ng} / \mathrm{mL}$, respectively. The average ratio of concentrations of testosterone to epitestosterone in urine was 2.64 (range: 0.42-4.40).
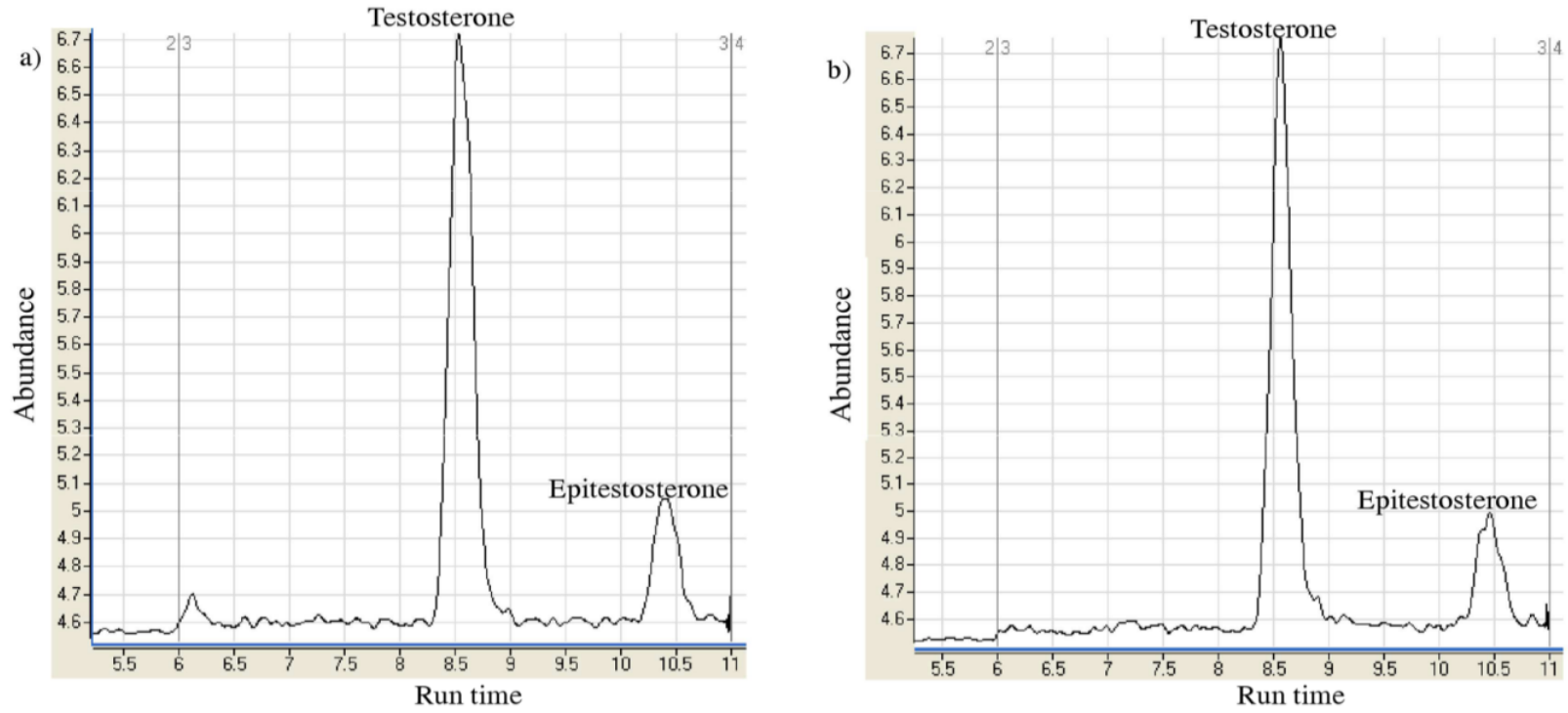

Figure 1: Chromatograms of testosterone and epitestosterone from a) plasma and b) urine at $0.250 \mathrm{ng} / \mathrm{mL}$ LLOQ concentration level for epitestosterone. 


\begin{tabular}{|c|c|c|c|c|c|c|}
\hline \multirow[t]{2}{*}{ Matrix } & \multirow[t]{2}{*}{ Compound } & \multirow{2}{*}{$\begin{array}{c}\text { Concentration } \\
(\mathrm{ng} / \mathrm{mL})\end{array}$} & \multirow[t]{2}{*}{ Level } & \multicolumn{2}{|c|}{ Precision RSD (\%) } & \multirow{2}{*}{$\begin{array}{c}\text { Accuracy } \\
(\%)\end{array}$} \\
\hline & & & & $\begin{array}{c}\text { Intra-day } \\
\mathrm{N}=6\end{array}$ & $\begin{array}{c}\text { Inter-day } \\
\mathrm{N}=18\end{array}$ & \\
\hline \multirow{8}{*}{ Urine } & \multirow{4}{*}{ Testosterone } & 0.25 & LLOQ & 10.01 & 10.11 & 107.03 \\
\hline & & 1.9 & Low & 2.66 & 5.51 & 96.61 \\
\hline & & 15.6 & Medium & 4.20 & 10.29 & 104.02 \\
\hline & & 250 & High & 1.13 & 3.39 & 97.11 \\
\hline & \multirow{4}{*}{ Epitestosterone } & 0.25 & LLOQ & 1.25 & 9.56 & 100.50 \\
\hline & & 1.9 & Low & 1.05 & 4.36 & 100.39 \\
\hline & & 15.6 & Medium & 8.17 & 8.94 & 96.45 \\
\hline & & 250 & High & 1.67 & 3.70 & 102.60 \\
\hline \multirow{8}{*}{ Plasma } & \multirow{4}{*}{ Testosterone } & 0.25 & LLOQ & 8.14 & 8.21 & 109.14 \\
\hline & & 1.9 & Low & 3.94 & 4.26 & 98.26 \\
\hline & & 15.6 & Medium & 5.47 & 5.92 & 102.66 \\
\hline & & 250 & High & 1.86 & 2.29 & 96.55 \\
\hline & \multirow{4}{*}{ Epitestosterone } & 0.25 & LLOQ & 2.58 & 6.87 & 98.20 \\
\hline & & 1.9 & Low & 1.44 & 2.96 & 103.01 \\
\hline & & 15.6 & Medium & 7.05 & 6.50 & 98.29 \\
\hline & & 250 & High & 1.82 & 3.19 & 100.86 \\
\hline
\end{tabular}

Table 2: Inter-day and intra-day accuracy and precision for the detection of testosterone and epitestosterone in urine and plasma.

\begin{tabular}{|c|c|c|c|}
\hline Matrix & Compound & $\begin{array}{l}\text { Concentration } \\
(\mathrm{ng} / \mathrm{mL})\end{array}$ & $\begin{array}{l}\% \text { Extraction } \\
\text { recovery }(\mathrm{N}=6)\end{array}$ \\
\hline \multirow{8}{*}{ Plasma } & \multirow{4}{*}{ Testosterone } & 0.25 (LLOQ) & 94.49 \\
\hline & & 1 & 81.63 \\
\hline & & 4 & 85.60 \\
\hline & & 16 & 85.98 \\
\hline & \multirow{4}{*}{ Epitestosterone } & 0.25 (LLOQ) & 92.77 \\
\hline & & 1 & 89.67 \\
\hline & & 4 & 84.72 \\
\hline & & 16 & 89.48 \\
\hline \multirow{8}{*}{ Urine } & \multirow{4}{*}{ Testosterone } & 0.25 (LLOQ) & 91.23 \\
\hline & & 1 & 87.63 \\
\hline & & 4 & 88.29 \\
\hline & & 16 & 89.16 \\
\hline & \multirow{4}{*}{ Epitestosterone } & 0.25 (LLOQ) & 92.57 \\
\hline & & 1 & 91.44 \\
\hline & & 4 & 89.60 \\
\hline & & 16 & 90.16 \\
\hline
\end{tabular}

Table 3: Absolute extraction recovery results for testosterone and epitestosterone in plasma and urine.

\begin{tabular}{|l|c|c|c|c|}
\hline Compound & $\begin{array}{c}\text { Concentration } \\
(\mathbf{n g} / \mathbf{m L})\end{array}$ & $\begin{array}{c}\text { Extracted } \\
\text { plasma }(\mathbf{n g} / \mathbf{m L}) \\
\mathbf{N = 6}\end{array}$ & $\begin{array}{c}\text { Extracted } \\
\text { urine }(\mathbf{n g} / \mathbf{m L}) \\
\mathbf{N = 6}\end{array}$ & $\begin{array}{c}\text { Standard in } \\
\text { acetonitrile } \\
(\mathbf{n g} / \mathbf{m L}) \mathbf{N}=6\end{array}$ \\
\hline \multirow{3}{*}{ Testosterone } & $0.25(\mathrm{LLOQ})$ & 0.248 & 0.241 & 0.250 \\
\cline { 2 - 5 } & 1 & 0.977 & 0.952 & 0.957 \\
\cline { 2 - 5 } & 2 & 2.019 & 2.005 & 2.053 \\
\hline \multirow{2}{*}{ Epitestosterone } & 8 & 8.089 & 8.129 & 8.455 \\
\cline { 2 - 5 } & 2 & 1.002 & 1.094 & 0.992 \\
\cline { 2 - 5 } & 2 & 2.051 & 1.961 & 1.977 \\
\hline & 8 & 8.038 & 8.122 & 8.110 \\
\hline
\end{tabular}

Table 4: Matrix effect of plasma and urine on spiked testosterone and epitestosterone compared with standard concentrations in acetonitrile.

The results highlighted a variation in urinary testosterone and epitestosterone in rats. Albeit observed in a small sample, there were also variations in the ratios as the majority of rats had values higher than those which have been found in humans shown to be around a 1:1 ratio with variations [16]. A number of factors could be considered for the variations in testosterone and epitestosterone concentrations

\begin{tabular}{|c|c|c|c|c|}
\hline Matrix & Compound & $\begin{array}{c}\text { Concentration } \\
(\mathrm{ng} / \mathrm{mL})\end{array}$ & $\begin{array}{c}\text { Extracted spiked } \\
\text { steroid in matrix } \\
(\mathrm{ng} / \mathrm{mL})\end{array}$ & $\begin{array}{c}\text { De-conjugated steroid } \\
\text { concentration } \\
(\mathrm{ng} / \mathrm{mL})\end{array}$ \\
\hline \multirow{6}{*}{ Urine } & \multirow{3}{*}{ Testosterone } & 1 & 0.98 & 0.91 \\
\hline & & 2 & 2.08 & 2.03 \\
\hline & & 15 & 16.96 & 14.03 \\
\hline & \multirow{3}{*}{ Epitestosterone } & 1 & 1.09 & 1.15 \\
\hline & & 2 & 2.11 & 2.14 \\
\hline & & 15 & 16.18 & 14.85 \\
\hline \multirow{6}{*}{ Plasma } & \multirow{3}{*}{ Testosterone } & 1 & 1.02 & 1.09 \\
\hline & & 2 & 2.04 & 2.07 \\
\hline & & 15 & 15.81 & 15.29 \\
\hline & \multirow{3}{*}{ Epitestosterone } & 1 & 1.08 & 0.96 \\
\hline & & 2 & 1.97 & 1.94 \\
\hline & & 15 & 15.87 & 15.06 \\
\hline
\end{tabular}

Table 5: The concentration of testosterone and epitestosterone after de-conjugation by $\beta$-glucuronidase compared to standard concentrations of extracted testosterone and epitestosterone in plasma matrix.

\begin{tabular}{|l|c|c|c|c|}
\hline Matrix & Animal & Testosterone & Epitestosterone & Ratio \\
\hline \multirow{4}{*}{ Urine $(\mathrm{ng} / \mathrm{mL})$} & 1 & 280.30 & 75.65 & 3.71 \\
\cline { 2 - 5 } & 2 & 615.22 & 160.46 & 3.83 \\
\cline { 2 - 5 } & 3 & 142.64 & 48.32 & 2.95 \\
\cline { 2 - 5 } & 4 & 71.63 & 16.28 & 4.40 \\
\cline { 2 - 5 } & 5 & 36.80 & 86.14 & 0.42 \\
\cline { 2 - 5 } & Average & 63.46 & 125.37 & 0.51 \\
\hline
\end{tabular}

Table 6: Concentrations of testosterone and epitestosterone in rat urine \pm SEM of triplicate injections.

\begin{tabular}{|l|c|c|c|c|}
\hline Matrix & Animal & Testosterone & Epitestosterone & Ratio \\
\hline \multirow{3}{*}{ Serum $(\mathrm{ng} / \mathrm{ml})$} & 1 & $386.39 \pm 6.268$ & $1.70 \pm 0.286$ & 227.89 \\
\cline { 2 - 5 } & 2 & $378.84 \pm 17.143$ & $1.64 \pm 0.129$ & 230.69 \\
\cline { 2 - 5 } & 3 & $318.52 \pm 1.517$ & $1.40 \pm 0.025$ & 227.12 \\
\cline { 2 - 5 } & 5 & $381.15 \pm 15.214$ & $2.11 \pm 0.065$ & 180.26 \\
\cline { 2 - 5 } & 6 & $378.80 \pm 8.662$ & $1.55 \pm 0.028$ & 244.54 \\
\cline { 2 - 5 } & Average & $363.40 \pm 11.615$ & $1.75 \pm 0.118$ & 212.01 \\
\hline
\end{tabular}

Table 7: Serum testosterone and epitestosterone in rats after the fourth week of sample collection \pm SEM of triplicate injections.

between individual animals. One factor might be the alterations and differences in metabolic rate of these steroids. Another factor is possibly due to the amount of water consumed by the rats as this can change drug levels in the body. These variations, and the deviation from the ratio typically observed in humans can greatly affect clinical trials thus warrant attention.

Table 7 shows the testosterone and epitestosterone concentrations in the sera of six rats. The average concentration of testosterone was $363.40 \pm 11.615 \mathrm{ng} / \mathrm{mL}$ and epitestosterone was $1.75 \pm 0.118 \mathrm{ng} / \mathrm{mL}$. The average testosterone to epitestosterone ratio was 212.01 (range: 161.54-230.69). The T/E ratio in the serum was a markedly higher than in urine owing to the high testosterone and low epitestosterone concentration in all animals.

These results showed that there was less variation in concentration in the serum samples compared to the urine samples probably due to individual differences in water consumption. Previous methods have been reported but with limitations such as validated applications to either urine [17-20] or serum [21] only; and with an extraction method taking greater than 1 hour [21]. In comparison, the new method benefits from improved resolution [19] and the reduced requirement for 
sample volumes [20,21]. This report of a straightforward novel method of rapid analyses of testosterone and epitestosterone in both rat urine and sera benefits from a new rapid liquid-liquid extraction procedure, suitable for both biofluids. Unlike the predecessors, the proposed method streamlines experimental in vivo designs where simultaneous monitoring of testosterone and epitestosterone in both urine and blood is required, such as investigating the effect and consequences of altered metabolic function in testosterone and epitestosterone glucuronidation [7-10]. The new method also eliminates potential confounding effects from applying multiple methods to cater for multiple sample matrices.

\section{Conclusions}

A method has been described here for the validation and detection of the anabolic steroids testosterone and epitestosterone in rat serum and urine at low $\mathrm{ng} / \mathrm{mL}$ concentrations using LC-MS/MS. This method shows optimal conditions for the de-conjugation of the steroid glucuronides to detect both free and conjugated steroids. In addition, this method has a good extraction recovery rate for both steroids allowing for accurate concentration determination by the use of the internal standard, stanozolol-D3.

Whilst methods have been described for the detection of testosterone and epitestosterone in humans $[17,18]$, this method provides deconjugation and extraction procedures affording detection of testosterone and epitestosterone concentrations in rat serum and urine. This method could be used in future research to investigate testosterone and epitestosterone metabolism in vivo. Furthermore, it could also be extended to detect steroids in human serum and urine samples to confirm urinary levels of these compounds used in sports doping tests. This technique could also be applied to measure metabolism patterns of steroids in vivo in place of the current method used by WADA which specifies measurements acquired by gas chromatography tandem mass spectrometry [22]. An advantage is that the LC method could be incorporated into forensic toxicology software to take full advantage of drug testing by LC MS/MS.

\section{References}

1. The World-Anti Doping Agency: The 2014 Prohibited List-International Standard.

2. Sottas PE, Saugy M, Saudan C (2010) Endogenous steroid profiling in the athlete biological passport. Endocrinol Metab Clin North Am 39: 59-73, viii-ix.

3. The World-Anti Doping Agency: 2012 Anti-Doping Testing Figures Report.

4. Stárka L (2003) Epitestosterone. J Steroid Biochem Mol Biol 87: 27-34.

5. Sten T, Finel M, Ask B, Rane A, Ekström L (2009) Non-steroidal antiinflammatory drugs interact with testosterone glucuronidation. Steroids 74 : 971-977.

6. Schulze JJ, Lundmark J, Garle M, Skilving I, Ekström L, et al. (2008) Doping test results dependent on genotype of uridine diphospho-glucuronosyl transferase 2B17, the major enzyme for testosterone glucuronidation. J Clin Endocrinol Metab 93: 2500-2506.

7. Deshmukh N, Petróczi A, Barker J, Székely AD, Hussain I, et al. (2010) Potentially harmful advantage to athletes: a putative connection between UGT2B17 gene deletion polymorphism and renal disorders with prolonged use of anabolic androgenic steroids. Subst Abuse Treat Prev Policy 5: 7.

8. Jakobsson J, Ekström L, Inotsume N, Garle M, Lorentzon M, et al. (2006) Large differences in testosterone excretion in Korean and Swedish men are strongly associated with a UDP-glucuronosyl transferase 2B17 polymorphism. J Clin Endocrinol Metab 91: 687-693.

Citation: Jenkinson C, Deshmukh NIK, Shah I, Zachár G, Székely AD, et al. (2014) LC-MS/ MS-Based Assay for Free and Deconjugated Testosterone and Epitestosterone in Rat Urine and Serum. J Anal Bioanal Tech S5: 006. doi:10.4172/2155-9872.S5-006
9. Jenkinson C, Petroczi A, Barker J, Naughton DP (2012) Dietary green and white teas suppress UDP-glucuronosyltransferase UGT2B17 mediated testosterone glucuronidation. Steroids 77: 691-695.

10. Jenkinson C, Petroczi A, Naughton DP (2012) Red wine and component flavonoids inhibit UGT2B17 in vitro. Nutr J 11: 67.

11. Mackenzie PI (1987) Rat liver UDP-glucuronosyltransferase. Identification of cDNAs encoding two enzymes which glucuronidate testosterone dihydrotestosterone, and beta-estradiol. J Biol Chem 262: 9744-9749.

12. Ikushiro S, Emi Y, Iyanagi T (1997) Protein-protein interactions between UDP glucuronosyltransferase isozymes in rat hepatic microsomes. Biochemistry 36 7154-7161.

13. Deshmukh NI, Zachar G, Petróczi A, Székely AD, Barker J, et al. (2012) Determination of stanozolol and 3'-hydroxystanozolol in rat hair, urine and serum using liquid chromatography tandem mass spectrometry. Chem Cent J 6: 162.

14. Deshmukh NI, Barker J, Petroczi A, Naughton DP (2012) Detection of testosterone and epitestosterone in human hair using liquid chromatographytandem mass spectrometry. J Pharm Biomed Anal 67-68: 154-8.

15. Deshmukh N, Hussain I, Barker J, Petroczi A, Naughton DP (2010) Analysis of anabolic steroids in human hair using LC-MS/MS. Steroids 75: 710-714.

16. Catlin DH, Hatton CK, Starcevic SH (1997) Issues in detecting abuse of xenobiotic anabolic steroids and testosterone by analysis of athletes' urine. Clin Chem 43: 1280-1288.

17. He C, Li S, Liu H, LiK, Liu F (2005) Extraction of testosterone and epitestosterone in human urine using aqueous two-phase systems of ionic liquid and salt. $J$ Chromatogr A 1082: 143-149.

18. Borts DJ, Bowers LD (2000) Direct measurement of urinary testosterone and epitestosterone conjugates using high-performance liquid chromatography/ tandem mass spectrometry. J Mass Spectrom 35: 50-61.

19. Zhan Y, Musteata FM, Basset FA, Pawliszyn J (2011) Determination of free and deconjugated testosterone and epitestosterone in urine using SPME and LC-MS/MS. Bioanalysis 3: 23-30.

20. Levent A, Altun A, Yardim Y, Sentürk Z (2014) Sensitive voltammetric determination of testosterone in pharmaceuticals and human urine using a glassy carbon electrode in the presence of cationic surfactant. Electrochimica Acta (In Press).

21. French D (2013) Development and validation of a serum total testosterone liquid chromatography-tandem mass spectrometry (LC-MS/MS) assay calibrated to NIST SRM 971. Clin Chim Acta 415: 109-117.

22. The World-Anti Doping Agency (2004) WADA Technical DocumentTD2004EAAS. Reporting and evaluation guidance for testosterone, epitestosterone, T/E ratio and other endogenous steroids.

\section{Submit your next manuscript and get advantages of OMICS} Group submissions

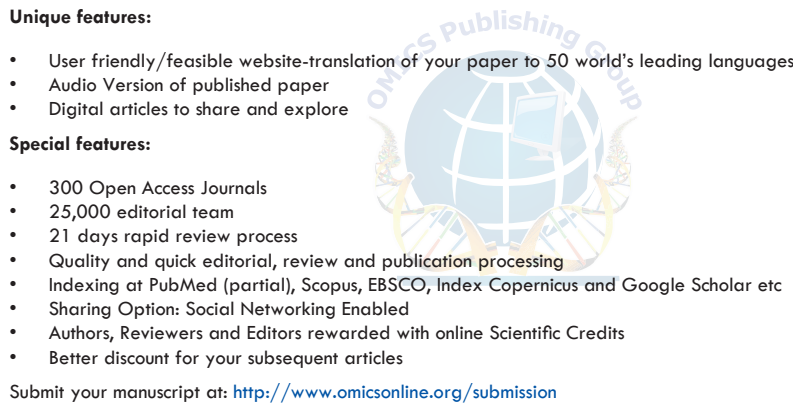

